\title{
Violencia, subjetividad masculina y justicia en la Ciudad de México $(1931-1941)^{*}$
}

\author{
Violence, Masculine Subjectivity \\ and Justice in Mexico City (1931-1941)
}

\author{
Martha Santillán Esqueda \\ (D) https://orcid.org/0000-0002-0414-2490 \\ Centro de Interdisciplinario de Investigación en Humanidades \\ Universidad Autónoma del Estado de Morelos \\ martha.santillan@uaem.mx
}

Resumen: A partir del estudio de las experiencias y concepciones individuales, sociales, jurídicas y médicas a través de dos asesinatos de pareja, se analiza la construcción de subjetividades masculinas en relación con la violencia. Parto del supuesto de que la violencia contra las mujeres formaba parte de las sociabilidades del periodo y que, aun cuando se experimentaban cambios sociales, políticos y jurídicos que limitaban los atentados sangrientos, al tiempo que se alentaba el desarrollo de las mujeres en el ámbito público, no se resquebrajan los esquemas patriarcales ni la autoridad masculina. Los asesinatos estudiados no son casos aislados, se entienden en relación con procesos sociales amplios a través de los cuales los individuos configuraron sus subjetividades

* Agradezco a Florencia Gutiérrez, Fausta Gantús y Julia Constantino, así como a los integrantes de los seminarios Historia Sociocultural de la Transgresión y el de Salud, Historia y Sociedad Contemporánea, las lecturas a borradores preliminares; igualmente valiosas fueron las observaciones de los dictaminadores y de la doctora Zenia Yébenes. Este artículo se inscribe en el marco del proyecto PRODEP 511-6/18-8990.

Cómo ciTAR: Santillán Esqueda, M. (2019). Violencia, subjetividad masculina y justicia en la Ciudad de México (1931-1941). Secuencia (104), e1614. DoI: https://doi.org/10.18234/secuencia.v0i104.1614

c) Esta obra está protegida bajo una Licencia Creative Commons Atribución-NoComercial 4.0 Internacional. 
y dieron sentido a sus acciones. Son escasos los trabajos historiográficos que estudian la construcción de la subjetividad masculina relacionada con la violencia, especialmente en el periodo propuesto.

Palabras clave: género; violencia; subjetividad masculina; justicia penal.

Abstract: Based on a study of individual, social, legal and medical experiences and conceptions in two domestic murders, an analysis is conducted of the construction of male subjectivities through violence. It is grounded in the assumption that violence against women was part of contemporary sociabilities, and that although social, political and legal changes took place that limited bloody attacks and encouraged the development of women in the public sphere, patriarchal frameworks and male authority remained intact. The murders studied are not isolated cases, but understood in relation to broader social processes through which individuals shaped their subjectivities and gave meaning to their actions. Very few historiographical articles study the construction of male subjectivity in connection with violence, in particular in the period proposed.

Key words: gender; violence; male subjectivity; criminal justice.

Fecha de recepción: 30 de abril de 2018 Fecha de aceptación: 13 de octubre de 2018

\section{INTRODUCCIÓN: UNA ESTRANGULACIÓN Y UNA PISTOLA}

U na mañana de mayo de 1934, Miguel Baez salió al encuentro de su mujer Consuelo Carrillo mientras ella caminaba por la calle; discutieron y la ahorcó. Siete años después, en febrero de 1941, Cuauhtémoc Granda se presentó afuera de la fábrica donde trabajaba su ex novia María Antonieta Fuentes; al encontrarse con ella discutieron y le dio tres tiros por la espalda.

Ambos asesinatos se enmarcan en una época de tensiones políticas y sociales, heredados del siglo anterior, que provocaban un reajuste en las iden- 
tidades de género ${ }^{1} y$, por tanto, en las formas de interacción entre los sexos. Tras la lucha revolucionaria las elites en el poder se dieron a la tarea de reorganizar las instituciones políticas y económicas, así como de implementar el marco legal acorde con los ideales de justicia. ${ }^{2}$ En este afán, jurídicamente se promovió una mejor situación para las mexicanas en materia constitucional, civil y laboral, que les posibilitó ir teniendo una participación más notoria en actividades fuera del ámbito privado a lo largo de las primera mitad del siglo XX (Santillán Esqueda, 2014), lo que de alguna manera alteraba las prerrogativas que los varones tenían sobre las mujeres.

Por otro lado, la masculinidad ideal, cifrada en la importancia del patrimonio-trabajo, las asociaciones de hombres, el hogar y el honor, además del control de las emociones (Miranda Guerrero, 2006), se revestía con los nuevos ideales posrevolucionarios en el marco del "retórico mejoramiento social" propio del periodo: "la representatividad de la familia, el cuidado de los bienes, el ser proveedor de la esposa y los hijos, y sobre todo, el ejercicio de la autoridad" (Muñiz, 2002, pp. 56 y 78). En tanto, a través del cine y la canción popular se iba delineando la figura del charro, símbolo de lo mexicano, como el hombre valiente, fanfarrón, pendenciero, trabajador, mujeriego y "muy querendón” (Pérez Montfort, 1994, p. 142); estampa muy ligada al también novedoso estereotipo del macho mexicano, hombre capaz de enfrentar los riesgos y desafíos a través del uso de la fuerza física (Macías y Rubenstein, 2012, p. 267). ${ }^{3}$

La modificación de la vida nacional estimuló un importante despliegue de esfuerzos materiales y discursivos en aras del establecimiento de determinado tipo de conductas individuales afines a los intereses políticos, económicos y éticos defendidos por el Estado posrevolucionario. Los años treinta

${ }^{1}$ Por identidades entiendo un espacio simbólico referencial en tensión y movimiento a partir del cual los sujetos orientan y conforman su subjetividad y, por tanto, sus acciones; es la "instauración de diversos límites o marcas que permiten al sujeto ubicarse como Uno", con referencia a diversos planos de orden simbólico, entre ellos, el de género (Serret, 1992, p. 152 y 2002, p. 28; Trueba, 2004, p. 75). Asumo como subjetividad el "conjunto de modos de percepción, afecto, pensamiento, deseo y temor que animan a los sujetos actuantes" (Ortner, 2016, p. 127).

${ }^{2}$ Se emitieron, entre otros ordenamientos jurídicos, dos códigos penales (1929 y 1931), el Código Civil de 1932 (1928), la Ley Federal del Trabajo (1931), la Ley General de Población (1936).

${ }^{3}$ Entre los escasos estudios historiográficos sobre la construcción de las masculinidades en México para la primera mitad del siglo xx, encontramos los de Gauss (2009), que estudia las masculinidades en el ámbito laboral; de Macías y Rubenstein (2012), que coordinan trabajos en torno a las sexualidades, y de Macías (2006), que se ocupa de los manuales de urbanidad. 
se caracterizaron por la difusión de la educación, el impulso del trabajo y la creación de instituciones públicas; ${ }^{4}$ a la par que los gobiernos promovieron el desarrollo de un pensamiento científico que apuntara a la comprensión de las conductas humanas para la configuración de un nuevo tipo de ciudadano (Urías Horcasitas, 2007). Con ello, se fueron fortaleciendo instituciones de control social y definiendo una ética posrevolucionaria que se sistematizaba con las propuestas eugenésicas e higienistas a favor de la familia, y cifradas en la idea de la salud pública y la eliminación de prácticas envilecedoras y perniciosas (alcoholismo, delincuencia, prostitución, por ejemplo). Al respecto, discusiones de juristas, criminólogos y psiquiatras abonaron a la conformación de los conceptos del sujeto peligroso y de la defensa social, sobre todo para casos de delitos violentos que les parecían excesivos o injustificados. ${ }^{5}$

Para la mayoría de los especialistas, los atentados contra las personas eran de origen fisiológico, psicológico o producto de la miseria. La violencia se equiparaba, sobre todo la sangrienta, con un estado "primitivo, instintivo e irreflexivo, sin elaboración intelectual", aseguraba Alfonso Quiroz Cuarón (1958, p. 43), conocido como el padre de la criminología moderna en México. Afirmaba que la pobreza era un ingrediente preponderante para cometer este tipo de delitos: "somos violentos por pobres y no por mexicanos. Por pobres no tenemos los mecanismos adecuados para frenar los impulsos que provienen del primitivo yo profundo, que es, ante todo, instintivo y brutal" (p. 45). Con todo, aunque era bastante aceptada la creencia de que los comportamientos agresivos eran producto de una falta de civilidad o modernización, vinculada a magras condiciones económicas y de moralidad, también se aseveraba que podían ser controlados. De cualquier manera, en el caso de los varones las conductas violentas "eran una práctica mediante la cual se jerarquizaba la hombría", además de ser una forma de poner "a prueba la fuerza y, sobre todo, de cuidar la reputación” (Pulido Esteva, 2017, p. 94).

Ahora bien, por más cruenta que resultara la violencia, ciertamente no era producto de una falta de "civilidad" o de ciegas pulsiones, como tampoco exclusiva de entornos de pobreza o de un sexo en específico o del machismo. Para los hombres el ejercicio de conductas agresivas podía significar la vía

${ }^{4}$ Por ejemplo, el Departamento de Psicopedagogía e Higiene (1925), el Tribunal de Menores (1928) o El Hospital de Toxicómanos (1932). Muñiz (2002, pp. 78, 155 y ss.).

${ }^{5}$ Muchas de las discusiones teóricas al respecto se plasmaron en dos importantes órganos científicos de difusión del conocimiento criminológico y psiquiátrico: Criminalia. Revista de Sociología Criminal (1933) y la Revista Mexicana de Psiquiatría, Neurología y Medicina Legal (1934). 
más apropiada para solventar determinado tipo de situaciones personales. Dado que la "violencia se activa" por múltiples causas en razón del contexto, al tiempo que se tolera y se regula en función de las distintas concepciones relacionadas con sus usos (Muchembled, 2010), ¿qué vicisitudes llevaron a Miguel y a Cuauhtémoc a asesinar a sus parejas? ¿Cómo fueron percibidos sus actos por ellos mismos, por jueces y por médicos? y, en última instancia, ¿cómo es que se elaboraban los procesos de subjetivación masculina en torno a la violencia?

Dado que las normativas de género del periodo planteaban que la virilidad se construía a través de la autoridad y del uso de la fuerza, se llegaba a consentir -tanto social como penalmente- el despliegue de agresiones masculinas en determinadas circunstancias; por ejemplo cuando se ejercía en el ámbito doméstico o en defensa del honor o la reputación. ${ }^{6}$ En contraparte, se asumía que las mujeres eran naturalmente dóciles, sentimentales y menos proclives a las conductas agresivas. El criminólogo Armando M. Raggi (1941) afirmaba que "la ciencia moderna ha evidenciado las íntimas relaciones que existen entre la 'constitución' somática, el 'temperamento' y el 'carácter' [... por ello] los sujetos que se conceptúan fuertes acostumbran a reaccionar en forma directa, rectilínea y 'agresiva”' (p. 443). Los asesinatos perpetrados por Miguel y Cuauhtémoc se explican porque, como varones, se asumían física y socialmente más fuertes que sus parejas, pero también con derecho a intervenir en sus conductas.

Bajo el entendido de que existía una concepción dicotómica de los sexos, en donde la autoridad del varón sobre la mujer era reconocida socialmente, en el presente artículo estudio experiencias y concepciones individuales, sociales, jurídicas y médicas sobre el asesinato de mujeres. La finalidad es analizar la construcción de las subjetividades masculinas en el marco de dos homicidios vinculados al honor y al amor, en un momento de cambios jurídicos y sociales que posibilitaban el desarrollo de las mexicanas fuera del espacio doméstico, lo que debilitaba las prerrogativas masculinas sobre las mujeres. En tal sentido, sostengo que aun cuando los gobiernos posrevolucionarios buscaron restringir en cierta medida las violencias mortales de los

${ }^{6}$ Para el penalista Mariano Ruiz Funes (1944), el honor estaba vinculado a la "integridad civil" de las personas y eran delitos en su contra aquellas acciones que "pon[ían] en peligro o perturba[n] la paz interior de la persona o el disfrute de aquella paz social, que queda sensiblemente quebrantada por el descrédito" (p. 726). 
hombres contra las mujeres, no se propugnó por una modificación radical de las estructuras de género patriarcales, con lo cual se continuó reconociendo el despliegue de este tipo de comportamientos como característicos de la hombría. En consecuencia, el origen de la violencia masculina no fueron los cambios sociales y políticos, como tampoco la autonomía que en el periodo adquirían las mujeres, sino componentes de un proceso más amplio y complejo en el que se reconfiguraba el entendimiento -individual, social y político- de aquellos ataques mortales.

Sirviéndome de ambas causas judiciales, centro la atención, por un lado, en el análisis cualitativo y la comprensión de la superposición de discursos especializados (psiquiátricos, criminológicos, penales y judiciales) que se vuelven el marco de referencia a partir del cual los sujetos significaron y resignificaron sus agresiones mortales. Y, por otro, busco averiguar, a través de los relatos de los procesados (localizados en declaraciones, peritajes psiquiátricos, escritos personales, que conforman el proceso penal) y con base en concepciones sociales más amplias, cómo justificaban sus acciones.

\section{EL CONTEXTO JURÍDICO. DOS HOMICIDIOS Y UN MOTIVO}

Miguel y Consuelo llevaban varios años casados y habían tenido dos hijos varones (uno había fallecido); al momento del homicidio ella estaba embarazada. Entre las desavenencias del matrimonio se contaban los periodos de escaso trabajo para Miguel y, en consecuencia, de poco dinero para la familia. Ángel Luna, compadre de ambos, y Conrado, hermano de Consuelo, los habían apoyado económicamente durante temporadas. La cercanía de Ángel despertó en Miguel la sospecha de un amorío entre este y su esposa. Así que un día, ante la insistencia de su mujer para que saliera más temprano de casa, se fue a trabajar con antelación. Decidió esperar en la calle para observar lo que ella haría en su ausencia. Consuelo salió con su hijo, lo dejó en una jabonería y caminó hacia el hotel Sol Inn; poco antes, su compadre había descendido de un autobús a escasos metros del hotel. Al ver todo esto, Miguel decidió encarar a Consuelo. Él afirmó que ella le reveló que en efecto sostenía una relación amorosa con Ángel, que el hijo que llevaba en el vientre era de este y que estaba dispuesta a irse con su amante. Tras esta confesión, Miguel dijo haber sufrido un "trauma psíquico" que lo llevó, "impulsado por una 
fuerza ciega e incontenible [...a] apretar fuertemente el cuello de mi esposa hasta dejarla sin vida". ${ }^{7}$

En cuanto a Cuauhtémoc y María Antonieta, tras casi tres años de noviazgo, él, a diferencia de ella, decía seguir perdidamente enamorado. Los pocos disgustos que existieron entre la pareja, que sostenía relaciones sexuales, se debían, dijo, a la insistencia de María Antonieta "por ser moderna": fumaba y andaba en bicicleta, además de vestirse con "zancón", lo que llevaba "las miradas de los hombres hacia sus piernas". Cuauhtémoc aseguró que las desatenciones de ella ante sus llamados para corregir aquellos comportamientos, así como el hecho de que colocara a su familia por encima de él, le fueron desencadenando con el tiempo los celos y una ira cada vez más difícil de controlar. María Antonieta terminó definitivamente la relación el día en que él le dio un puntapié y una cachetada a su hermana. Cuauhtémoc, "cansado, hambriento, extenuado, desvelado, loco, en el colmo de la desesperación”, fue a buscarla cuando ella salía de trabajar para "rogarle" una vez más que lo perdonara. La tomó del brazo pero ella se desprendió con "un jalón de mano [...] dirigiéndole una mirada despreciativa", le dio la espalda y lo dejó ahí parado con la "boca abierta”. Entonces Cuauhtémoc utilizó la pistola que llevaba en el saco. ${ }^{8}$

En 1931 había entrado en vigor un código penal de tendencia ecléctica que formulaba sus preceptos desde los postulados teóricos del liberalismo jurídico, de la escuela positivista, el materialismo histórico, la sociología, el humanismo y la biología (Teja Zabre, 1936, p. 8). ${ }^{9}$ Dicho ordenamiento proponía que los delitos eran actos voluntarios resultado tanto del medio social y económico como de las condiciones étnicas y biológicas del sujeto. Alfonso Teja Zabre (1936) aseguraba en la exposición de motivos que no existían delincuentes sino seres humanos que no son buenos o malos por naturaleza, sino

${ }^{7}$ Miguel Báez Graibelt. Homicidio (apelación vs. sentencia acusatoria). 11 de marzo de 1935. Fondo Tribunal Superior de Justicia del Distrito Federal. Archivo Histórico 1. Caja 3830, exp. 460378, f. 5. Archivo General de la Nación (en adelante AGN), México.

${ }^{8}$ Cuauhtémoc Granda Viramontes. Homicidio. 19 de febrero de 1941. Fondo Tribunal Superior de Justicia del Distrito Federal. Archivo Histórico 2. Caja 356, exp. 54, fs. 15-17v, 75. AGN, México.

9 El Código Penal de 1871 pertenecía a la doctrina liberal y entendía el delito como una violación voluntaria al contrato social, por lo tanto se castigaba al delincuente en función de la transgresión penal cometida. El código de 1929 se adscribía a la escuela positivista y consideraba que el delincuente actuaba por factores ajenos a su voluntad, por lo que se castigaba en función de la peligrosidad del criminal antes que por el delito cometido. Para una mejor comprensión de las transformaciones que sufrieron los códigos penales en México del porfiriato a la posrevolución, véase Speckman (2008c). 
producto de las circunstancias (pp. 8 y 11). De acuerdo con Elisa Speckman (2008c), los redactores consideraban que el delincuente era como cualquier otro ser humano, y aunque no expresaron una afinidad por los determinismos orgánicos, aseguraban que los factores sociales, económicos, étnicos y biológicos de las personas podían afectar su voluntad al momento de delinquir (pp. 602-605).

En el código el delito era entendido como un hecho contingente de múltiples causas, "resultante de fuerzas antisociales", definido como el "acto u omisión que sancionan las leyes penales", que podía ser intencional o imprudencial (no intencional). Era intencional cuando voluntariamente se ejecutaba una conducta tipificada por el código y no intencional cuando por negligencia, impericia o falta de reflexión se cometían conductas delictivas (arts. 7 y 8). Asimismo, se amplió el arbitrio de los jueces al ensancharse los márgenes de las penas; por lo que se esperaba que aplicaran castigos acordes a las circunstancias sociales, económicas y personales del sujeto delincuente en relación con la comisión del acto criminal.

En el artículo 15 se precisaban las excluyentes de responsabilidad penal que eximían de toda sanción a quienes cometían delitos de manera involuntaria o prisioneros de situaciones emocionales. En la fracción II se determinaba la inimputabilidad cuando el acusado se hallaba "al cometer la infracción, en un estado de inconciencia de sus actos, determinado [...] por un trastorno mental involuntario de carácter patológico y transitorio". En la fracción III se exculpaban los actos delictivos cuando en legítima defensa de la vida, del honor o de los bienes, se ejecutaban para repeler "una agresión actual, violenta, sin derecho y de la cual resulte un peligro inminente". En la fracción IV, si había mediado un miedo grave o temor fundado e irresistible ante "un mal inminente y grave" para "salvar su propia persona o bienes o la persona o bienes de otro", también había disculpa.

Speckman (2018) considera que los casos de homicidio en que se aludía a la legítima defensa del honor o de la vida eran más comunes en las defensas de hombres que de mujeres, ya que este acto exigía de voluntad, y en los hombres no se reconocía tan fácilmente la existencia de actitudes temerosas o cobardes. En contraparte, a las mujeres se les defendía en general bajo la figura del miedo grave que implicaba la ausencia de voluntad, conciencia, discernimiento, reflexión, en tanto que la persona actuaba en estado de inconsciencia o, al menos, de conciencia disminuida por algún trauma (pp. 443-444). Ambos discursos están vinculados a las concepciones de género de la época: 
la masculinidad implicaba autoridad, fuerza, honor, voluntad; la feminidad, debilidad, temor $y$, en todo caso, sensibilidad emocional.

Por otro lado, en el artículo 68 del ordenamiento penal se precisaba que "los locos, idiotas, imbéciles, o los que sufran cualquiera otra debilidad, enfermedad o anomalía mentales, y que hayan [delinquido] serán recluidos en manicomios o en departamentos especiales, por todo el tiempo necesario para su curación". Así, respecto al estado mental y/o emocional de un presunto delincuente como coadyuvante del crimen, estas eran las únicas cláusulas contempladas por el código penal para interpretar su caso judicial.

Tales figuras penales posibilitaban establecer la existencia de un tipo de delincuentes "especiales" cuando se demostrara científicamente que la acción criminal acontecía en el contexto de un estado emocional o mental atípico. Ello implicaba establecer que los límites de la justicia penal se fijaban cuando el criminal había delinquido sin intención o bajo el influjo de una emoción desordenada provocada por un factor ajeno a -y que anulara- su voluntad.

Miguel fue sentenciado a dos años y un mes de prisión por homicidio en caso de adulterio; es decir, su delito fue considerado un homicidio atenuado. ${ }^{10}$ No obstante, con esta sentencia no alcanzaba el beneficio de la condena condicional $;{ }^{11}$ de modo que era fundamental convencer al tribunal de segunda instancia que el acto criminal había acontecido en un contexto donde él fue presa de emociones superiores que lo llevaron, sin haberlo deseado y de manera irremediable, a cometer el crimen. Para ello, en la apelación (redactada y firmada por él mismo ${ }^{12}$ ) sostenía haber sufrido una obnubilación mo-

${ }^{10}$ El homicidio calificado -con premeditación, alevosía, traición y ventaja- se castigaba entre trece y 20 años de cárcel (art. 315); el simple, con entre ocho y trece años (art. 307); en los casos de asesinato en riña, el provocado recibía hasta la mitad de la sanción del homicidio simple y el provocador hasta cinco sextos (art. 308). El asesinato perpetrado contra un cónyuge, al ser sorprendido(a) en "acto carnal o próximo a su consumación", se castigaba con entre tres días y tres años de prisión (art. 310). Esta última sanción aplicaba para el padre que mataba al corruptor de su hija bajo su potestad, siempre y cuando lo hiciere "en el momento de hallarlos en el acto carnal o en uno próximo a él" (art. 311).

${ }^{11}$ Cuando la sanción otorgada era menor a dos años, el delincuente era primario, tenía un modo honesto de vivir y observaba en general buena conducta, la Corte podía concederle el beneficio de la condena condicional, esto es, cubrir la sentencia fuera de prisión pagando una fianza o caución (art. 90).

${ }^{12}$ El hecho de que Miguel haya redactado su apelación es valioso para el análisis cultural e ideológico, aun cuando su narrativa haya estado mediada por el lenguaje jurídico y, seguramente, bajo el consejo de uno o varios abogados (quienes a fin de cuentas eran los encargados de "traducir" los intereses de sus clientes en términos procesales, legales y de jurisprudencia). 
mentánea tras las confesiones de su esposa (art. 15, fracción II), que lo impelió a defender su honor (art. 15, fracción III). Aseguró haber actuado

impulsado por una fuerza ciega o incontenible que me hizo apretar fuertemente del cuello de mi esposa hasta dejarla sin vida; el trastorno mental e involuntario [...] fue provocado por un enardecimiento que me privó de todo raciocinio muy común en nuestro medio y sobre todo en tipos del carácter pasional y emotivo como lo es el del suscrito; estos impulsos ciegos en temperamentos nerviosos provocan la inconciencia a la que llegué sin buscar ningún arma para castigar la infidelidad de mi esposa.

[...]

mi honor de hombre que siempre he cuidado de cumplimiento de sus deberes, de improviso se vio agredido por el conocimiento de los actos próximo al adulterio de la señora Carrillo y la confesión plena que me hizo, en forma tan provocativa, constituyó la agresión que es requisito indispensable para la excluyente de responsabilidad de defensa legítima. ${ }^{13}$

En el caso de Cuauhtémoc, el Ministerio Público en la acusación formal pidió a la Corte de sentencia que se aplicara el artículo 68, con lo cual sería internado en el manicomio general La Castañeda. Sin embargo, el defensor sostuvo que el procesado no estaba loco, por lo que sí era responsable del homicidio. Insistía en que su cliente, dados sus antecedentes personales y las circunstancias del crimen, merecía la pena mínima, castigo ya compurgado pues llevaba año y medio en prisión preventiva. Con esta argucia el abogado pretendía su liberación definitiva.

En los inicios del proceso la parte defensora solicitó un peritaje, el cual fue realizado por los psiquiatras José Quevedo y Jesús Siorda, quienes afirmaron que existía en Cuauhtémoc un determinismo delictivo vinculado a un estado epiléptico. Por su parte, el agente del Ministerio Público solicitó un dictamen a los médicos legistas Alberto Lozano Garza y Erasmo Marín quienes confirmaron que el homicida en efecto tenía una personalidad psico-

Ello no demerita el valor simbólico de los dichos consignados en los procesos judiciales ya que son parte $-y$ por tanto representativos- de imaginarios culturales amplios a partir de donde se elaboran y se reconocen socialmente los procesos de subjetivación.

${ }^{13}$ Miguel Báez Graibelt. Homicidio (apelación vs. sentencia acusatoria). 11 de marzo de 1935. Fondo Tribunal Superior de Justicia del Distrito Federal. Archivo Histórico 1. Caja 3830, exp. 460378, fs. 5-6. AGN, México. 
pática epileptoide o explosiva, pero que de ninguna manera había cometido el crimen mecánicamente y en ausencia de voluntad, por lo que su culpa era imputable y él merecedor de castigo penal. No obstante, consideraban que debía ser atendido en un hospital psiquiátrico por las condiciones mentales y la psicosis carcelaria que ya presentaba.

En consecuencia, el juez solicitó un tercer estudio al psiquiatra Edmundo Buentello (director de La Castañeda entre 1944 y 1945). ${ }^{14}$ Tras un examen exhaustivo que incluía encefalograma, punciones cerebrales, largas entrevistas con el procesado y charlas con amigos y familiares, el especialista confirmó que Cuauhtémoc era un epiléptico típico y lo calificó como un enfermo mental que presentaba "accidentes psicóticos intensos, que son en sí mismos, un padecimiento mental transitorio". ${ }^{15}$ Esto, sumado a la existencia de relaciones sexuales entre la pareja, ${ }^{16}$ desordenó, según el especialista, el estado emocional de Cuauhtémoc que derivó en la comisión del crimen:

La actitud sentimental de C. hacia A. no es pues la de un sujeto hacia su novia, sino hacia su amante. Los resultados psíquicos son diferentes. En el primer caso la tendencia es hacia la posesión, la conservación de intacta virginidad, preservación de malas compañías, celos de quien pudiera interesarse igualmente por ella, etc. En el segundo se trata de la conservación de algo que ya se considera en el medio mexicano habitual, como posesión inalienable, pues de otra suerte hay baldón para el honor y la hombría. [...] Con esta constelación de hechos medulares y circunstanciales sobreviene la una ruptura de las relaciones [...]. Esto trae como consecuencia, rebeldía de parte de C. ${ }^{17}$

En ambos casos, el detonador de la violencia estuvo relacionado con el control de las mujeres, la sexualidad femenina y el honor masculino dentro de una relación de pareja. Para Pablo Piccato (2010), a principios del siglo Xx la violencia contra las mujeres se cifraba no sólo en las tradiciones patriarca-

${ }^{14}$ Sección Expedientes de personal. Fondo Manicomio General. Leg. 3, exp. 3. Archivo Histórico de la Secretaría de Salud (en adelante AHSs), México.

15 Cuauhtémoc Granda Viramontes. Homicidio. 19 de febrero de 1941. Fondo Tribunal Superior de Justicia del Distrito Federal. Archivo Histórico 2. Caja 356, exp. 54, f. 118. AGN, México.

${ }^{16}$ En la autopsia del cadáver se descubrió que María Antonieta tenía algunas semanas de embarazo y llevaba introducida una sonda para abortar.

${ }_{17}$ Cuauhtémoc Granda Viramontes. Homicidio. 19 de febrero de 1941. Fondo Tribunal Superior de Justicia del Distrito Federal. Archivo Histórico 2. Caja 356, exp. 54, f. 110. AGN, México. 
les, sino también en un ambiente urbano en transformación caracterizado por "la inseguridad laboral, la migración y un régimen autoritario". En consecuencia, "la inestabilidad marital y la necesidad de controlar la fuerza de trabajo familiar eran los factores que, en este contexto, otorgaban sentido a la violencia privada" (p. 174).

No obstante, y en concordancia con Robert Buffington (2005), considero que la violencia masculina contra las mujeres no es consecuencia exclusiva de tales transformaciones o bien del deseo masculino de poder o del supuesto machismo mexicano. En las postrimerías del porfiriato el autor demuestra que "funciona[ba] de forma sistémica más que de manera aislada y es típica más que aberrante" (pp. 288-289). En otras palabras, los asesinatos aquí estudiados no se agotan en su "finalidad instrumental" (Segato, 2010, p. 44). Deben entenderse incorporados a un sistema de género en el cual la violencia formaba parte de los procesos de subjetivación masculina $;{ }^{18}$ en todo caso, como veremos más adelante, los cambios políticos y sociales experimentados tras la revolución reorientaron el sentido sociosimbólico de la violencia.

$\mathrm{Al}$ analizar la "dimensión psicológica" del fenómeno en el entre siglo, Buffington (2005) encuentra un notorio énfasis, tanto en la prensa popular como en los dichos de los agresores, en alusión a la existencia de una "violencia psíquica hacia los hombres (en lugar de la violencia física hacia las mujeres)" (p. 319). ${ }^{19}$ En este mismo sentido, tanto Miguel como Cuauhtémoc, asumidos a sí mismos como víctimas de sus parejas, tenían un motivo similar para cometer el homicidio: la rebeldía femenina, en un momento de creciente y alentada "liberación" de las mexicanas, que en consecuencia menguaba el poder masculino sobre las mujeres.

${ }^{18}$ García Peña (2017a) ha demostrado que con la creación de los marcos jurídicos liberales mexicanos a partir del siglo xix se legalizó la autoridad masculina sobre las mujeres, que incluía el uso de la violencia. Ciertamente, los estados liberales refrendan su poder a través del propio derecho que emana de sus gobiernos y que se erige en torno a relaciones de desigualdad entre los sexos; de ahí que el estado liberal "siempre patriarcal, no pued[a] dejar de serlo" (Segato, 2016, p. 105).

${ }^{19}$ Estudios sociológicos recientes muestran cómo en la actualidad "muchos hombres creen [...] que los actos de diversidad y pluralidad de los otros representan actos de desafío y maltrato hacia ellos" (Garda, 2007, p. 641). 


\section{CAMBIOS SOCIALES. DOS MUJERES Y UN DESORDEN MASCULINO}

La última frase que Consuelo dijo a Miguel previo a su muerte fue que él era "un agachón". María Aguayo, testigo de la defensa, aseguró que alguna vez vio a Consuelo salir de un hotel y que en otra ocasión ella le preguntó "si sabía donde había casas malas porque su marido ya la tenía aburrida". Alberto Rico, compañero de escuela de Consuelo, afirmó que desde entonces "era afecta a tratos con los hombres; que ya casada, se pudo dar cuenta de que tenía un carácter fuerte" ${ }^{20}$ Con estas declaraciones se buscaba dejar en claro que el carácter altanero, ingobernable e inmoral de Consuelo fue el motivo de su muerte.

En el caso de María Antonieta la justificación fue el desprecio y su conducta libertina. La tía de Cuauhtémoc consideraba que ella, por ser "bonita y mayor, ejercía mucha presión sobre el muchacho hasta sacarlo de sus quehaceres y obligaciones". Le disgustaba que ella fuese "demasiado libre" y "en exceso insinuante", tanto que en su ausencia se había atrevido a entrar a su casa a "hurtadillas una ocasión a tomar copas y pasteles" a solas con su sobrino. Tras un disgusto entre los enamorados, María Antonieta se fue a Yurécuaro con su familia. Cuauhtémoc le escribió desesperado: "te mando la presente con el fin de que me contestes, pues mira nena, tú bien comprendes que cuando me has castigado en esta forma ni como, ni duermo, ni me presento a clases, [...] Amor mío perdóname, no seas cruel". ${ }^{21}$

La agresión mortal perpetrada por Miguel y Cuauhtémoc contra sus parejas va mucho más allá de un acto individual que compete exclusivamente al carácter de sujetos aislados de su entorno. Por el contrario, es justamente el contexto social lo que posibilita y condiciona la configuración de sus subjetividades, es decir, de sus maneras de existir y actuar. Vidas como estas "revelan de qué manera lo posible se hace efectivo en los procesos sociales, es decir, lo que hemos acabado considerando históricamente factible en un determinado tiempo y lugar" (Zemon-Davis, 1991, p. 179).

${ }^{20}$ Miguel Báez Graibelt. Homicidio (apelación vs. sentencia acusatoria). 11 de marzo de 1935. Fondo Tribunal Superior de Justicia del Distrito Federal. Archivo Histórico 1. Caja 3830, exp. 460378, fs. 10-11. AGN, México.

${ }^{21}$ Cuauhtémoc Granda Viramontes. Homicidio. 19 de febrero de 1941. Fondo Tribunal Superior de Justicia del Distrito Federal. Archivo Histórico 2. Caja 356, exp. 54, fs. 19 y 80. AGN, México. 
Bajo el entendido de que el accionar de los individuos "presupone una subjetividad compleja en la que el sujeto internaliza en parte y reflexiona en parte sobre una serie de circunstancias en las que se encuentra y contra las que, en este caso, finalmente reacciona" (Ortner, 2016, p. 148), cabe preguntarse qué caracterizaba la violencia de los varones contra las mujeres hacia la década de los años treinta en México, y cómo es que esta se construía y adquiría sentido sociosimbólico. ${ }^{22}$

Los homicidios de Miguel y de Cuauhtémoc -como muchos otros similares- no son "una voluntad originaria o natural, sino que adopta[n] la forma de deseos o intenciones específicos dentro de una matriz de subjetividad, de sentimientos, pensamientos y significados (culturalmente construidos)" (Ortner, 2016, p. 131). Sus conductas se producen en un México que experimentaba transformaciones políticas, jurídicas y sociales que beneficiaban de manera importante a las mujeres y que, en consecuencia, desafiaban valores del sistema patriarcal heredado del siglo anterior, pero que a su vez no dejaba de reconocer la autoridad -y con ello justificaba ciertas violencias- de los varones sobre las mujeres. En principio, la modificación del marco jurídico tras la revolución otorgó a las mexicanas el derecho a trabajar y a la educación sin necesidad del consentimiento del padre o del marido. Respecto a la familia, los cambios fueron importantes y favorecedores para la autonomía y el proceso de individuación femenina.

De acuerdo con el Código civil de 1932 (1928), "la equiparación legal entre el hombre y la mujer se hacía necesaria”. Es decir, negar el nuevo papel social de las mujeres implicaba ir a contracorriente de otros países donde las mujeres ya no estaban relegadas exclusivamente al hogar (Motivos del Código, 1928, pp. 11-13). A diferencia del porfiriato, se dispuso que las mexicanas tuvieran la misma facultad que el esposo dentro del matrimonio para administrar y disponer de los bienes, así como para tomar decisiones sobre la educación de los hijos. También podrían mantener la patria potestad de los vástagos, celebrar cualquier tipo de contrato y posibilitarse un empleo; todo esto siempre y cuando no descuidaran la dirección y los trabajos del hogar. ${ }^{23}$ En tanto, la manutención de la familia continuaba siendo obligación de los varones (art.

${ }^{22}$ Para Natalie Zemon-Davis "no hemos de buscar significados en las acciones de los individuos sino en los conceptos que las explican” (Pascua Sánchez, 2013, pp. 104-105).

${ }^{23}$ Estas consideraciones habían sido ya establecidas en la Ley de Relaciones Familiares de 1917, aunque esta todavía presentaba algunas desventajas para las mujeres (Santillán Esqueda, 2016, p. 129). 
164). El ordenamiento contemplaba el divorcio vincular y las mismas causales de separación para ambos cónyuges (art. 267). En los dos códigos penales posrevolucionarios (1929 y 1931) no se hacía distinción alguna entre el adúltero y la adúltera; el delito sólo existía cuando provocaba escándalo o se consumaba en el domicilio conyugal y se castigaba hasta con dos años de prisión (Santillán Esqueda, 2016, pp. 160-169).

Por otro lado, los gobiernos posrevolucionarios fueron promoviendo un reordenamiento del hogar a través de la injerencia de agentes externos del Estado (representantes escolares, judiciales, de salud pública, médicos, psiquiatras, pedagogos) que orientaban la conformación de familias y ciudadanos sanos física y mentalmente (Stern, 2002). Ello posibilitó la reconfiguración del dominio doméstico y, por tanto, un grado de autonomía de las mujeres frente a sus parejas. Si bien este proceso, tal como anota Alexandra Stern (2002), tenía como finalidad la procreación de niños sanos en el marco de la familia -entendida como el basamento social en donde la actividad femenina debía seguir funciones precisas relacionadas con la maternidad y la administración del hogar-, lo cierto es que con la creación de instituciones, normativas y reglamentaciones, diseñadas por especialistas, también se reacomodaba la línea de autoridad patriarcal y disminuían los campos de acción del varón al interior del hogar.

En aquel complejo escenario, los cambios sociales también contrastaban con el aumento del número de mujeres desarrollándose fuera del ámbito doméstico (en el mundo del trabajo, la educación, y actividades culturales y políticas) que, aunque no era abrumador, sí era palmario. ${ }^{24}$ En tal sentido, las "nuevas" mujeres llegaban a resultar peligrosas porque podían depender menos de los varones, cuestionaban su autoridad, los engañaban y los descontrolaban emocionalmente. ${ }^{25} \mathrm{El}$ hecho de que las mexicanas se "modernizaran" y que buscaran desarrollarse a través de actividades ajenas al espacio doméstico -y que tuvieran la protección y el aliento legal para ello-, suponía una importante alteración en las relaciones de género existentes. La dificultad de esta situación para los varones podía estribar en que ello estaba avalado por las nuevas posturas del Estado.

24 Existen diversos trabajos historiográficos sobre mujeres en México que abordan los avances de las mujeres y los cambios en la concepción de género en el siglo xx. Para una revisión general pueden consultarse Lamas (2007); Porter (2008), y Santillán Esqueda (2008, 2014).

${ }_{25}$ Para un análisis sobre el temor que generaba la mujer moderna, a través del análisis de la figura de la vampiresa en los filmes, véase Santillán Esqueda (en prensa). 
García Peña (2006) ha demostrado que en el porfiriato el maltrato a las mujeres era una práctica generalizada, social y jurídicamente aceptada, pues era esperado -cuando no deseado- que los varones ejercieran la autoridad moral que tenían para someter a sus esposas. Tanto en los usos y costumbres como en las leyes, las mujeres debían obediencia a sus maridos, y cuando alguna "actuaba con libertad de movimiento, libertad financiera, libertad de propiedad y libertad de interrelacionarse con cualquiera, provocaba los actos violentos en su contra" (pp. 66-91). ${ }^{26}$ En las primeras décadas del siglo Xx, a pesar de las novedosas propuestas jurídicas, no se mostró "ninguna preocupación real por el asunto de las mujeres violentadas" (García Peña, 2017a, p. 204).

Para el periodo que nos ocupa, aunque más limitado, el control de los varones sobre las mujeres continuaba siendo una conducta pertinente. De ellas, a pesar de los cambios, se esperaba recato y obediencia hacia los hombres. Entonces, cuando ciertos comportamientos cuestionaban el dominio de los hombres con quienes estaban relacionadas (padre, esposo, hermanos, hijos), las respuestas violentas se podían asumir como un "instrumento legítimo para garantizar, ante la mirada pública, el honor de los hombres y la sumisión de las mujeres" (Piccato, 2010, p. 188). De tal suerte, la virilidad continuaba afirmándose, aunque en un marco de mucha tensión por las nuevas limitaciones, en función del honor y su autoridad tanto al interior del hogar como en la intimidad de la pareja.

Para Segato (2016) la violencia ejercida por hombres es preciso entenderla como un "mandato" que alude "al imperativo y a la condición necesaria para la reproducción del género como una estructura de relaciones entre posiciones marcadas por un diferencial jerárquico [...]. Se trata de un acto necesario en los ciclos regulares de restauración de ese poder" (p. 13). Dicho de otro modo, los varones que matan, como Miguel y Cuauhtémoc, lo hacen no porque pueden sino porque deben hacerlo para demostrar su hombría "en cuanto compuesto indiscernible de masculinidad y subjetividad" (p. 40). Si bien para los años posrevolucionarios la violencia masculina contra las mujeres no se exacerba, tampoco buscaba ser erradicada, simplemente adquiría particularidad en función de los cambios en el marco jurídico que, además de promover una mejor situación para las mexicanas, tendía a limitar determi-

${ }^{26}$ Carmen Ramos Escandón (2004) realiza un estudio sobre la forma en que a las mexicanas se les fueron reduciendo sus derechos jurídicos a favor del aumento de la autoridad masculina sobre las mujeres. 
nados tipos de ataques en su contra. De tal modo que el esquema patriarcal, si bien se reacomodaba dando un nuevo significado a las agresiones, mantenía incólume los procesos de subjetivación masculina vinculados del "mandato" del empleo de la violencia.

\section{SUBJETIVIDAD MASCULINA: VIOLENCIA, HONOR Y AMOR}

Los jueces del Tribunal Superior de Justicia ratificaron la sentencia otorgada por la Corte Penal de Primera Instancia de dos años de cárcel y un mes de prisión por homicidio en caso de adulterio para Miguel. Aseguraron que aceptar los alegatos del procesado para ser exculpado, ya fuera por defensa del honor o por haber actuado de manera involuntaria, constituiría "no un adelanto, sino el anacronismo de que frente a la dignificación y libertad de la mujer moderna, de que tanto se hace alarde, se levantara el marido de la época medieval, con derechos de vida y muerte sobre la esposa" ${ }^{27}$

A pesar de todos los cambios jurídicos, socialmente el honor masculino continuaba viéndose fuertemente violentado con la infidelidad femenina, pues esta dejaba en entredicho la hombría al demostrar la incapacidad del varón para controlar a sus mujeres. Sirva de ejemplo el escarnio social que se evidencia en el "látigo moral" de los refranes populares: "el que nace para buey, del cielo le caen los cuernos” (Fernández Poncela, 2002a, pp. 73-75). A decir de María Elvira Bermúdez (1955), escritora adscrita a la corriente de la filosofía de lo mexicano en la década de los cincuenta, las mujeres en las cuales un hombre había decidido "poner los ojos" debían mantenerse leales e incólumes a su imagen y recuerdo, de lo contrario corrían el riesgo de "ser tildadas de livianas; y en ocasiones, de perder la vida” (p. 52).

En la prensa roja muchos de los homicidios que involucraban relaciones afectivas o de pareja fueron catalogados como pasionales y se caracterizaban por centrar el conflicto en infidelidades, celos o desamor. En general, los varones eran quienes más cometían este tipo de asesinatos y solían ser representados como víctimas que tenían que salvaguardar su honor previamente

${ }^{27}$ Miguel Báez Graibelt. Homicidio (apelación vs. sentencia acusatoria). 11 de marzo de 1935, Fondo Tribunal Superior de Justicia del Distrito Federal. Archivo Histórico 1. Caja 3830, exp. 460378 , f. 14 . AGN, México. 
agredido (Núñez Cetina, 2016). Cabe mencionar que el "homicidio pasional" no estaba tipificado penalmente. Lo que se consideraba en términos judiciales era la existencia de pasiones violentas en la comisión de un asesinato, lo que podía atenuar los castigos o exculparlos en caso de ser reconocidos en el marco del artículo 15.

Es importante anotar que en general estos ataques sangrientos se enmarcaban en entornos domésticos o de pareja signados por la violencia más que por la pasión amorosa o el fortuito descontrol a raíz de una conducta sexual o amorosa inapropiada por una de las partes. De hecho, la mayoría de las mujeres que cometían homicidios lo hacían contra sus parejas en momentos de extrema violencia en los que la victimaria salía victoriosa de una agresión previa, la mayoría de las veces enmarcada en malos tratos recurrentes (Santillán Esqueda, 2017, pp. 235-245); y en muchas ocasiones, a pesar de que las homicidas, como sucedió a Vita Sierra Villanueva y Emma Perches Frank, interponían denuncias por agresiones físicas recibidas -anteriores a su crimen-y no eran atendidas por las autoridades (Speckman, 2018, pp. 460-478).

Ahora bien, en esa época no sólo la relación entre los sexos cambiaba, también las concepciones del honor. Si bien en el porfiriato no se concedía a las mujeres matar por honor o por celos ${ }^{28}$ para la década de los veinte fueron célebres los casos de mujeres (llamadas autoviudas) que mataron en defensa de su honor y fueron absueltas o recibieron penas atenuadas. ${ }^{29}$ Para los años treinta, el honor era considerado un bien que la ley debía proteger y no había a la letra ningún tipo de prerrogativa en función del sexo del victimario; sin embargo, había posturas al respecto. Algunos legisladores sostenían que la infidelidad femenina mancillaba el honor masculino, pero no al contrario; mientras que otros consideraban que el adulterio no empañaba el honor del cónyuge, fuese hombre o mujer (Speckman, 2016, p. 32).

En general, la tendencia judicial era estimar cada vez menos este tipo de asesinatos como inimputable por honor, sino más bien como homicidio

${ }^{28}$ Un caso emblemático, y recurrido por la historiografía del crimen en México, es el de María Villa, una prostituta que asesinó en 1897 a su contrincante de amores. A pesar de que María sostenía que había matado por celos, fue condenada a 20 años de prisión (pena máxima para las mujeres). Esto debido a que durante el porfiriato era labor de los varones recuperar el honor perdido de las mujeres (Buffington, 2001, pp. 101-13; Buffington y Piccato, 1999). En el código penal porfiriano de 1871 se estableció claramente que "la reputación de la mujer no se empaña por las faltas de su marido" (Speckman, 2016, p. 37).

${ }^{29}$ Véase Monroy Nasr (2018); Rojas Rebolledo (2008); Speckman (2008a, 2008b, 2016). 
por adulterio. Ante la ratificación de la sentencia recibida por Miguel, este se amparó argumentando que "sería absurdo admitir que la Ley penara al que mata cuando recibe de su cónyuge la confesión de infidelidad, y lo amenaza con irse con otro". Para él, sumado a la supuesta introducción de hijos ajenos al matrimonio, era inconcebible que todo esto no fuese considerado "una ofensa o agresión a su honor, sino simples palabras injuriosas, ofensas verbales o manifestaciones de desprecio, dando así a la palabra honor un sentido distinto del común y general de nuestra sociedad". Sin embargo, con los mismos argumentos que los jueces de sentencia, el amparo no le fue concedido: "es verdad que hay una franca agresión contra el derecho de fidelidad y que esta agresión es ilegítima, porque no la autoriza ningún precepto legal, ni las conveniencias sociales, pero aunque la agresión exista no autoriza la muerte, porque la defensa indica evitación y conservación y ya en este caso, el derecho que se defiende no existe por haber sido violado". ${ }^{30}$

En esa lógica, para Ángel Ceniceros y Luis Garrido (1934), miembros de la comisión redactora del Código Penal de 1931, el asesinato en definitiva no era "legítimo como sanción a la infidelidad"; desconocían en todos sentidos la potestad masculina para quitarle la vida a la esposa o la hija. Para los juristas, además, el código penal ya contemplaba un castigo para los adúlteros; de tal modo que, si se atenuaban los homicidios en caso de adulterio era porque consideraban a los victimarios como un criminal no peligroso y de ínfima temibilidad que actuaba en función de sentimiento "elevado" pero que podía ser controlado (pp. 69-70).

Por su parte, el reconocido abogado Raúl Carrancá y Trujillo (1937) lamentaba que hubiese colegas a favor de eximir estos homicidios y que incluso llegaran a validarlo en la práctica judicial. Para Carrancá y Trujillo no podía estimarse la infidelidad "como agresión contra el honor del marido" y por ello "el uxoricida en caso de adulterio representa de todas suertes un sujeto peligroso al que no se debe aplaudir"; este tipo de homicidios no buscaba, aseguraba, defender un derecho a la fidelidad conyugal sino vengarla (pp. 413-417). De ahí que Miguel insistiera en su derecho a castigar la infidelidad de su esposa. De cualquier manera, las penas impuestas por este tipo de homicidio eran bastante bajas: de tres días a tres años de cárcel, y con la posibilidad de

${ }^{30}$ Miguel Báez Graibelt. Homicidio (apelación vs. sentencia acusatoria). 11 de marzo de 1935. Fondo Tribunal Superior de Justicia del Distrito Federal. Archivo Histórico 1. Caja 3830, exp. 460378, fs. 20, 22 y 42v. AGN, México. 
compurgar la pena fuera de la prisión si el castigo impuesto era menor a dos años. Así, los cambios jurídicos no acontecían carentes de tensión y transitaban a un ritmo distinto a la vida social y cultural.

En primer lugar, es posible observar que a pesar de la mirada progresista de ciertos juristas, no había un interés real por erradicar la violencia masculina contra las mujeres ni por castigarla con vehemencia, sino más bien por limitarla en determinadas circunstancias porque no se ajustaba a los ideales masculinos hegemónicos. Por ejemplo, para el penalista Carlos Franco Sodi (1951) el hombre maltratador era un "símbolo de nuestra degeneración"; este "odioso ejemplar" era producto de la "impudicia social" (alcohol, vicios sexuales, ambición desmedida, brutalidad e ignorancia), por lo que era fundamental ejercer todo el rigor de la ley sobre este tipo de delincuentes (pp. 70-74). En segundo, se evidencia que las masculinidades eran discursos en litigio tanto al interior de diversos ámbitos (político, médico, jurídico, social, cultural) como entre ellos; pero también que la virilidad no se construía exclusivamente en el ejercicio de la autoridad, del poder y de la violencia.

Ahora bien, en el terreno de lo cultural para los años treinta las identidades masculinas se reconfiguraban dando prioridad al macho sentimental, difundido ampliamente a través del cine y de la industria musical de la época. Entre sus virtudes debía ser enérgico y belicoso, vengar afrentas contra su honor, pelear por mujeres y tratar de domesticarlas para amarlas y ser amado incondicionalmente por ellas; pero cuando no conseguía el amor de una mujer, el hombre sufría y se lamentaba amargamente (Domínguez Ruvalcaba, 2013, pp. 45-46).

Para estos años, con ideas deudoras del amor romántico, se promovía una concepción de amor de pareja unida por el afecto, afinidades, la búsqueda de la felicidad y más centrado en la intimidad emocional y sexual (García Peña, 2017b). El varón veía en su enamorada a una "compañera para toda la vida", con las cualidades necesarias para convertirse en esposa y madre; esto es, abnegada, amorosa, casta y supeditada a él moral, económica y sexualmente, y dedicada a los hijos y al hogar. Por su parte, una mujer para sentirse amada esperaba de un hombre "protección, seguridad y estabilidad [...] características que hacían posible pensar en la procreación y en la integración del hogar" (Torres Septién, 2007, pp. 400-403). Ahora bien, el noviazgo se caracterizaba idealmente, entre otras cosas, porque el vínculo debía estar exento de relaciones sexuales, las cuales debían esperar hasta el matrimonio. 
De este modo, había niveles de compromiso con una mujer y, por tanto, de autoridad sobre ella. Por ello es que para el psiquiatra Buentello, entre sus estimaciones sobre los detonantes de la violencia de Cuauhtémoc, en el marco de su salud mental, no era un dato menor el hecho de que la pareja tuviese relaciones sexuales. A entender del especialista, como se anotó más arriba, el nivel de posesión y, por tanto, de "baldón para el honor y la hombría" era mucho mayor para él, por lo que su respuesta resultó más violenta. Así, un hombre que había establecido relaciones sexuales con una mujer asumía tener derechos sobre ella, al tiempo que podía resultar más afectado en caso de involucramiento sentimental de su parte si había muestras de desapego de parte de ella.

En este esquema de relaciones sentimentales los varones eran la parte activa a quienes las mujeres, como agentes pasivos, debían satisfacer sentimental y sexualmente (Torres Septién, 2013, p. 447). La relación afectiva se convertía en un importante espacio donde los hombres cifraban su intimidad y sus sentimientos, para lo cual se requería de la colaboración femenina: una gran cantidad de la violencia masculina deriva "de la inseguridad y de la inadaptación más que de la perpetuación del dominio patriarcal. La violencia es una reacción destructiva a la mengua de la complicidad femenina”, asegura Giddens (1995, p. 115). El problema era justamente la libertad femenina también para el caso mexicano. Así, el fenómeno en el periodo que estudiamos, visto a través de las subjetividades de Miguel y Cuauhtémoc, tiene como centro importante la autonomía de las mujeres para desenvolverse en otros espacios y la disminución del control masculino sobre ellas.

Cuando hubo rupturas entre Cuauhtémoc y María Antonieta, él aseguraba que "sufría muchísimo tal como si una llaga se hubiera abierto en su corazón, que andaba descontrolado en todos los sistemas, que se pasaba las noches vagando, sin comer, sin dormir y con el convencimiento de que su vida sin ella era insoportable". Sin poder acercarse a ella porque era vigilada por sus familiares, optó por hablar con los dueños de la fábrica donde ella trabajaba para pedirles que lo dejaran verla, "que se pusieran de su parte en el aspecto moral", que estaba "enamoradísimo". La entrevista le fue concedida, pero María Antonieta lo rechazó una vez más. Después vino el desenlace mortal. Él se lo había advertido en aquella carta que envió a Yurécuaro durante el primer distanciamiento: "Mira mi vida, si no me arriesgo a matarte, es porque me pongo a pensar que si te mueres, ya ni tú ni yo podemos gozar de 
la vida, pudiendo hacerlo." Antes de descargar la pistola, las últimas palabras de Cuauhtémoc a su amada fueron "Toña ya no me quieres". ${ }^{31}$

Por supuesto que los crímenes por amor no son exclusivos de este periodo; sin embargo, tienen sus especificidades. El sentimiento amoroso, al igual que el apasionamiento, es una construcción cultural que adquiere forma a través de expresiones y deseos propios de un contexto histórico-social. Para el periodo posrevolucionario el amor era asumido como el elemento central en la unión de las parejas que conformarían una familia. Esta idea estaba bastante extendida y circulaba entre los discursos de especialistas (juristas, criminólogos, médicos, psiquiatras, pedagogos), de la Iglesia y de los medios de comunicación (películas, radionovelas, canciones populares, consultorios sentimentales y narraciones amorosas en revistas, la novela rosa, campañas publicitarias, etc.)..$^{32}$

El amor que se debían prodigar los involucrados consistía en idealizarse y adorarse (Careaga, 2012, p. 191), aunque en general en el discurso de la canción popular de la época el amor de pareja era "sentimentaloide" -y en ocasiones melodramático-, era una tarea dura y dolorosa (Fernández Poncela, 2002b, p. 135). Con la expansión del bolero y de la música ranchera, de la mano del teatro de revista, el radio y el cine, a partir de la segunda década del siglo $\mathrm{xx}$ se divulgaba un discurso amoroso cifrado en el dolor y el sufrimiento masculino a causa del desdén femenino.

En la canción ranchera los temas predilectos eran la traición, el desamor o la infidelidad; se reclamaba y culpabilizaba con un fuerte dolor la infamia de la mujer, quien en general recibía como castigo sólo el ser señalada por su perfidia (Fernández Poncela, 2002b, pp. 130-201): "me contaron tus amigos que te encuentras muy solita, que maldices a tu suerte porque piensas mucho en mí [...]. Dios me ha dado ese capricho y he venido a verte hundida para hacerte yo en la vida como tú me hiciste a mí." ${ }^{33}$ Hay un número importante de boleros en el que los hombres desean con ánimo de venganza que las mujeres sufran por no corresponder a su amor (Fernández Poncela, 2002b, p.

${ }^{31}$ Cuauhtémoc Granda Viramontes. Homicidio. 19 de febrero de 1941. Fondo Tribunal Superior de Justicia del Distrito Federal, Archivo Histórico 2. Caja 356, exp. 54, fs. 1v, 15, 16v y 19. AGN, México.

${ }^{32}$ Martha Eva Rocha (1995 y 1996) estudia los consultorios sentimentales y analiza los discursos amorosos y sus prácticas en las relaciones de pareja. Para una revisión de los contenidos y géneros de la radionovela de la época, véase Teresa Hernández García (1995).

33 Canción Ranchera Cuando el destino, de José Alfredo Jiménez, grabada en 1948. 
181): "yo sé que es imposible que me quieras que tu amor para mí fue pasajero [...] No creas tus infamias de perjura incitan mi rencor para olvidarte [...] tu castigo se lo dejo a Dios. " ${ }^{44}$ Es así como se evidencia, al igual que en las acciones de Miguel y Cuauhtémoc, la victimización masculina -y su consecuente venganza- ante la falta de colaboración de las mujeres con sus sentimientos, en un contexto donde los instrumentos jurídicos tendían a no favorecer sus deseos de represalia.

En aquellas concepciones de amor de pareja, los celos, el desamor y la traición femenina desempeñaban un papel fundamental en la construcción de las subjetividades masculinas. Con el advenimiento del amor romántico desde el siglo xIx los hombres quedaron excluidos del desarrollo de una intimidad sentimental. En opinión de Giddens (1995), para ellos enamorarse se trataba exclusivamente de técnicas de seducción y de conquista con un profundo desconocimiento de las necesidades sentimentales de las mujeres. En consecuencia, se generaba una sensación de incomprensión frente a la feminidad, construida precisamente a través de los afectos y las emociones (p. 62).

Para el caso mexicano una muestra de ello la da Octavio Paz (2000) en El laberinto de la soledad (publicado en 1950), cuando afirma que la mala mujer "va y viene, busca a los hombres, los abandona" (p. 175). Bajo la premisa de que la feminidad es un "enigma" para los hombres, el poeta se pregunta si "la mujer ¿esconde la muerte o la vida?, ¿en qué piensa?, ¿piensa acaso?, ¿siente de veras?, ¿es igual a nosotros?" (p. 203). Además, asegura que "el sadismo" contra la mujer "inicia como venganza ante el hermetismo femenino o como tentativa desesperada para obtener una respuesta de un cuerpo que tenemos insensible" (p. 203).

En un texto publicado en 1947 por El Universal, en el que se transcribía la carta de un lector, la articulista convenía en que había "un arma que calma instantáneamente a una mujer enfurecida [...] un palo grueso y resistente, y yo aconsejo a los recién casados lo adquieran sin más dilación" ${ }^{35}$ En la revista Juventud, patrocinada por Acción Católica, se aconsejaba a los jóvenes no escoger como esposa a la mujer "moderna" y "frívola", ya que esta era sinónimo de "liberalidad" y, por tanto, de prostitución (Torres Septién, 2007, p. 404). Así, aquel macho sentimental justificaba el sometimiento agresivo hacía una

${ }_{34}$ Bolero Imposible, Agustín Lara, s/f. Primer bolero del que se tiene registro del cantautor.

${ }^{35}$ E. Robinson, "Mujeres que necesitan una paliza de su esposo", El Universal, 21 de julio de 1947, p. 11. 
mujer por ser inicialmente víctima de ella (ente incomprensible, inasible -por ello incontrolable- $y$, en consecuencia, peligrosa por su falta de solidaridad con sus sentimientos y deseos del hombre).

La fortaleza y la seguridad, atributos viriles, quedaban en entredicho y los hombres se convertían en víctimas de las mujeres, únicas responsables de esa debilidad (Rosado Millán, 2009, pp. 9-10). Ello muestra un sistema patriarcal en tensión y una crisis de la masculinidad ante el reajuste en las relaciones de género, sin menoscabar el "mandato" para que los hombres mostraran su poder sobre las mujeres (imperativo fundamental en los procesos de subjetivación). En tal sentido, las agresiones en el periodo de estudio adquirían simplemente nuevas motivaciones y significados.

Antes de que Miguel recibiera la sentencia condenatoria del Tribunal Superior, se le había concedido la libertad bajo fianza en lo que el proceso penal seguía su curso. ${ }^{36}$ Tras la ratificación de su sentencia (de dos años y un mes de prisión) y del amparo no concedido, se giró orden judicial para su reaprehensión, pero no fue localizado. En el caso de Cuauhtémoc, los jueces de la Corte penal de primera instancia se apoyaron en el dictamen psiquiátrico de Buentello para definir que el procesado era inimputable por padecer de antemano un trastorno mental (art. 68); de modo que se giró orden para ser trasladado al manicomio general La Castañeda. No obstante, dado que también se le concedió la posibilidad de permanecer bajo la vigilancia de un tutor (art. 69), su madre lo recogió en prisión dos años después del homicidio.

\section{REFLEXIONES FINALES}

La violencia contra las mujeres en el periodo estudiado se encontraba bastante extendida en todas las clases sociales. La escritora Bermúdez (1955) lo atribuía a "la falta de respeto y de consideración del hombre hacia la mujer", lo que a su parecer era "la característica más frecuente de la familia media mexicana" (pp. 21 y 58). Hasta muy entrado el siglo xx, la violencia doméstica

${ }^{36} \mathrm{Si}$ al delito por el que se le dictaba formal prisión le correspondía una pena menor a cinco años, el acusado podía solicitar libertad bajo fianza o caución (en efectivo), lo que le permitía permanecer fuera de prisión durante el transcurso del proceso, de lo contrario debía permanecer detenido hasta que se dictara sentencia. Código de procedimientos penales (1931, art. 556). 
fue un tema pendiente en la agenda política y social, ${ }^{37}$ en todo caso quienes la denunciaban lo hacían concentrándose más en denostar la promiscuidad, el alcoholismo, las infidelidades, malos hábitos al interior de los hogares, la holgazanería masculina o el abandono del jefe de familia. En tanto, los hombres, a través de agresiones diversas, verbales o físicas, ejercían su autoridad con el fin de controlar a los integrantes de sus familias.

He insistido en que los asesinatos aquí analizados no son acciones de sujetos aislados, como tampoco son necesariamente violencias que buscaban restituir el orden patriarcal que advertía ajustes ante la autonomía femenina y las nuevas identidades masculinas propuestas por las elites. Los asesinatos de Consuelo y María Antonieta se entienden como el producto de procesos amplios que, al acotar los márgenes de autoridad masculina, justificaba su uso al asumirse los homicidas víctimas de las mujeres.

La violencia masculina contra las mujeres se ejercía en función de prerrogativas de dominación social y jurídica propia de los estados patriarcales liberales. Con los gobiernos posrevolucionarios se fueron implementando otras formas de control a través de leyes, instituciones y discursos científicos que promovían la existencia de un tipo de varón ad hoc a los ideales posrevolucionarios. En consecuencia, las masculinidades para los años treinta se advierten inestables en el marco de los cambios políticos y sociales acaecidos en aquellos años, lo que reconfigura el sentido sociosimbólico de la violencia contra las mujeres. Demostrar que la violencia contra las mujeres, al menos en este periodo, buscaba restituir el orden de género precedente y que por ello se exacerbaba, exigiría establecer cifras que permitan ver tendencias cuantitativas y cualitativas de los uxoricidios por adulterio desde el porfiriato $y$ durante la primera mitad del siglo xx.

Más bien, lo que se ha buscado en este trabajo es dar cuenta de los cambios en las identidades de género y cómo ello, en tensión con una serie de discursos sociales y jurídicos, orientaba la configuración de cierto tipo de subjetividades masculinas que, poco a poco, iban experimentando mayor restricción en el uso de la violencia contra las mujeres, aun cuando les fuese permitida -cuando no exigida en tanto hombres-. Por ello el problema de la autonomía femenina, más que agravar la violencia masculina, lo que posibilitó fue encauzarla en un sentido preciso: el de la victimización del macho

${ }^{37}$ La violencia doméstica comenzó a tomar relevancia a partir de la década de los setenta, ya que se le seguía considerando un asunto privado (Olmedo Dobrovolny, 1998). 
sentimental que reacciona violentamente ante el atentado a su honor y hombría por la infidelidad o el desamor de una mujer que podía controlar menos porque las mujeres ya tenían derechos para desarrollarse como personas de diferentes maneras, con lo cual disminuía la dependencia hacia el varón.

El hecho de que el homicidio por adulterio fuese menos procesado como legítima defensa del honor, habla de cambios importantes que se sucedían en aquel México. Sin embargo, la concepción de la infidelidad femenina como una afrenta a la virilidad era un tema fuertemente arraigado y relacionado con la autoridad masculina que, si bien legalmente experimentaba límites sin precedentes en ciertos aspectos de la vida familiar e íntima, no buscaba ser anulada. El varón, en términos morales y sociales, continuaba siendo una autoridad en el hogar y en la relación de pareja. En opinión de Elena Larrauri (1994), "el derecho penal no era divisado para castigar la violencia [masculina] sobre las mujeres, sino para limitarla" (p. 5); por ello es que este tipo de crímenes, aun cuando se castigaban, se hacía con penas muy bajas.

Sin embargo, el esquema patriarcal no se desmoronaba porque, aunque disminuida su autoridad, seguía siendo una facultad del hombre y la violencia un imperativo en la construcción de la subjetividad masculina. Así, la violencia contra las mujeres no recrudeció a consecuencia de los cambios sociales y jurídicos, sino que estos se convirtieron en el marco donde se construían las nuevas subjetividades masculinas cifradas en el "mandato" de violencia contra las mujeres propio de los estados patriarcales. La violencia en este periodo era parte de un sistema de género en transformación que no dejaba de reconocer su uso, de ahí que se atenuara el homicidio por adulterio y que muchas violencias al interior del hogar, como muestran los indicios recuperados por la historiografía, no llegaran a la justicia penal y se quedaran en lo privado (salvo en casos extremos, como la muerte).

\section{LISTA DE REFERENCIAS}

Bermúdez, M. E. (1955). La vida familiar del mexicano. México: Antigua Librería Robredo.

Buffington, R. (2001). Los criminales y ciudadanos en el México moderno. México: Siglo XXI Editores.

Buffington, R. (2005). La violencia contra la mujer y la subjetividad masculina en la prensa popular de la ciudad de México en el cambio de siglo. En C. Agostoni 
y E. Speckman (coords.), De normas y transgresiones, enfermedad y crimen en América Latina (1850-1950) (pp. 287-326). México: Instituto de Investigaciones Históricas-UNAM.

Buffington, R. y Piccato, P. (1999). Tales of two women: the narrative construal of porfirian reality. The Americas, 55(3), 391-424. Dor: 10.2307/1007648

Careaga, G. (2012). Mitos y fantasías de la clase media. México: Cal y Arena.

Carrancá y Trujillo, R. (1937). Derecho penal mexicano, parte general. México: Ed. Porrúa. Ceniceros, J. A. y Garrido, L. (1934). Ley penal mexicana. México: Ediciones Botas.

Código civil para el Distrito y Territorios Federales (1932) (1928). México: Imprenta Aldina.

Código de procedimientos penales para el distrito y territorios federales y para toda la república en materia de fuero federal (1931) (1931). México: Ediciones Botas.

Código Penal para el distrito y territorios federales en materia de fuero común y para toda la república en materia de fuero federal (1931) (1936). México: Ediciones Botas.

Domínguez Ruvalcaba, H. (2013). De la sensualidad a la violencia de género. La modernidad y la nación en las representaciones de la masculinidad en el México contemporáneo. México: CiesAs.

Fernández Poncela, A. M. (2002a). Estereotipos y roles de género en el refranero popular. México: Anthropos.

Fernández Poncela, A. M. (2002b). Pero vas a estar muy triste y así te vas a quedar. Construcciones de género en la canción popular mexicana. México: INAH.

Garda, R. (2007). Construcción social de la violencia masculina. Ideas y pistas para apoyar a los hombres que desean dejar su violencia. En A. Amuchástegui e I. Szasz (coords.), Sucede que me canso de ser hombre... relatos y reflexiones sobre hombres y masculinidades en México (pp. 653-681). México: El Colegio de México.

García Peña, A. L. (2006). El fracaso del amor. Género e individualismo en el siglo XIX mexicano. México: El Colegio de México/Universidad Autónoma del Estado de México.

García Peña, A. L. (2017a). La privatización de la violencia conyugal en la Cuidad de México entre los siglos xVIII y xx: polémicas del liberalismo. Intersticios Sociales, 14, 185-209.

García Peña, A. L. (2017b). Un divorcio secreto en la revolución mexicana: jtodo por una jarocha! México: El Colegio de México.

Gauss, S. M. (2009). La masculinidad de la clase obrera y el sexo racionalizado. Género y modernización en la industria textil de Puebla durante la época posrevolucionaria. En G. Cano, M. K. Vaughan y J. Olcott (comps.), Género, poder y política en el México posrevolucionario (pp. 281-305). México: Fondo de Cultura Económica/ Universidad Autónoma Metropolitana-Iztapalapa. 
Giddens, A. (1995). La transformación de la intimidad. Sexualidad, amor y erotismo en las sociedades modernas. Madrid: Cátedra.

Hernández García, T. (1995). Las diferentes épocas de auge de la radionovela en el Distrito Federal. (Tesis de licenciatura inédita). Facultad de Ciencias Políticas y Sociales-unAm, México.

Lamas, M. (comp.) (2007). Miradas feministas sobre las mexicanas del siglo Xx. México: Fondo de Cultura Económica/Conaculta.

Larrauri, E. (1994). Control informal; las penas de las mujeres. En E. Larrauri (comp.), Mujeres y derecho penal y criminología (pp. 1-17). Madrid: Siglo XXI Editores.

Macías, V. (2006). Hombres de mundo: la masculinidad, el consumo, y los manuales de urbanidad y buenas maneras. En M. T. Fernández Aceves, C. Ramos Escandón y S. S. Porter (coords.), Orden social e identidad de género. México, siglos XIX y Xx (pp. 267-397). México: ciesas-Guadalajara.

Macías, V. y Rubenstein, A. (2012). Masculinity and sexuality in modern Mexico. Albuquerque: University of New Mexico Press.

Miranda Guerrero, R. (2006). La vida de un obrero y la construcción de la masculinidad (1890-1940). En M. T. Fernández Aceves, C. Ramos Escandón y S. S. Porter (coords.), Orden social e identidad de género. México, siglos XIX y XX (pp. 299-321). México: CIESAs-Guadalajara.

Muñiz, E. (2002). Cuerpo, representación y poder. México en los albores de la reconstrucción nacional, 1920-1940. México: UAM-Azcapotzalco/Miguel Ángel Porrúa.

Monroy Nasr, R. (2018). María Teresa de Landa. Una miss que no vio el universo. México: INAH/Secretaría de Cultura.

Motivos del Código (1928). En Código civil para el distrito y territorios federales (1932). México: Imprenta Aldina.

Muchembled, R. (2010). Una historia de la violencia. Del final de la edad media a la actualidad. Madrid: Paidós.

Núñez Cetina, S. (2016). Los estragos del amor. Crímenes pasionales en la prensa sensacionalista de la Ciudad de México durante la posrevolución. Trashumante. Revista Americana de Historia Social, 7, 28-51. Dor: 10.17533/udea.trahs.n7a03

Olmedo Dobrovolny, J. (1998). Violencia intrafamiliar: un asunto de interés público. En P. Olamendi Torres (coord.). La lucha contra la violencia hacia la mujer: legislación, políticas públicas y compromisos de México (pp. 45-48). México: Unifem.

Ortner, Sh. (2016). Antropología y teoría social. Cultura, poder y agencia. Buenos Aires: UNSAM Edita.

Pascua Sánchez, M. J. de la (2013). Natalie Z. Davis o la historia de las mujeres desde una historia social renovada. Historia Social, 75, 95-112. 
Paz, O. (2000). El laberinto de la soledad. Madrid: Cátedra.

Pérez Montfort, R. (1994). Estampas del nacionalismo. Ensayos sobre cultura popular y nacionalismo. México: ciesas.

Piccato, P. (2010). Ciudad de sospechosos: crimen en la ciudad de México, 1900-1931. México: CIESAS/FONCA.

Porter, S. S. (2008). Mujeres y trabajo en la Ciudad de México. Condiciones materiales y discursos públicos (1897-1931). México: El Colegio de Michoacán.

Pulido Esteva, D. (2017). El "cantinismo": culturas del alcohol en la Ciudad de México, principios del siglo xx. Historias. Revista de la Dirección de Estudios Históricos, 96-97, 83-94.

Quiroz Cuarón, A. (1958). La criminalidad en la república. México: Instituto de Investigaciones Sociales-UNAM.

Raggi Ageo, A. M. (1941). La mujer y el delito. Criminalia. Revista de Sociología Criminal, viI(7), 437-448.

Ramos Escandón, C. (2004). Legislación y representación de género en la nación mexicana: la mujer y la familia en el discurso y la ley, 1870-1890. En S. E. Pérez-Gil Romo y P. Ravelo Blancas (coords.), Voces disidentes. Debates contemporáneos en los estudios de género en México (pp. 93-112) México: cIesAs/Miguel Ángel Porrúa/Cámara de Diputados.

Rocha, M. E. (1995). Consultorio sentimental. Paradigmas y comportamientos amorosos. En J. J. Blanco, Cuidado con el corazón. Los usos amorosos en el México moderno (pp. 143-162). México: INAH.

Rocha, M. E. (1996). Los comportamientos amorosos en el noviazgo, 1870-1968. Historias. Revista de la Dirección de Estudios Históricos, 35, 119-139.

Rojas Rebolledo, E. (2008). María Teresa Landa. En G. Villadelángel Viñas (coord.), Libro rojo, una continuación (vol. II, pp. 39-53). México: Fondo de Cultura Económica.

Rosado Millán, M. J. (2009). La debilidad masculina a través de los personajes de cine negro americano. Prisma Social. Revista de Ciencias Sociales, 3, 9-10.

Ruiz-Funes, M. (1944). El derecho al honor. Criminalia. Revista de Sociología Criminal, $\mathrm{X}(12), 718-733$.

Santillán Esqueda, M. (2008). Discursos de redomesticación femenina durante los procesos modernizadores en México, 1946-1958. Historia y Grafía, 31, 103-132.

Santillán Esqueda, M. (2014). Posrevolución y participación política. Un ambiente conservador (1924-1953). En A. Maza (coord.), De liberales a liberadas. Pensamiento y movilización de las mujeres en la historia de México (1753-1975) (pp. 151-195). México: Nueva Alianza. 
Santillán Esqueda, M. (2016). Mujeres y leyes posrevolucionarias. Un análisis de género en el código penal de 1931. Iter Criminis. Revista de Ciencias Penales, 13, 125-171.

Santillán Esqueda, M. (2017). Delincuencia femenina. Ciudad de México, 1940-1950. México: Instituto Mora/Instituto Nacional de Ciencias Penales.

Santillán Esqueda, M. (en prensa). Vampiresas. En G. Pulido y S. Sosenski (coords.), Hampones, pelados y pecatrices. Sujetos peligrosos en la Ciudad de México, 1940-1960. México: Secretaría de Cultura/Fondo de Cultura Económica.

Segato, R. L. (2010). Estructuras elementales de la violencia. Ensayos sobre género entre la antropología, el psicoanálisis y los derechos humanos. Buenos Aires: Prometeo.

Segato, R. L. (2016). La guerra contra las mujeres. Madrid: Traficantes de Sueños.

Serret, E. (1992). Género, familia e identidad cultural. Orden simbólico de la identidad femenina. En J. M. Valenzuela (coord.). Decadencia y auge de las identidades (cultura nacional y modernización). Tijuana: El Colegio de la Frontera Norte.

Serret, E. (2002). Identidad femenina y proyecto ético. México: PUEG-UNAM.

Sodi, F. (1951). Don Juan delincuente y otros ensayos. México: Impresora Juan Pablos.

Speckman, E. (2008a). Dos crímenes, dos víctimas: los casos de Alicia Olvera y Nidia

Camargo. En G. Villadelángel Viñas (coord.), Libro rojo, una continuación (vol. I, pp. 719-728). México: Fondo de Cultura Económica.

Speckman, E. (2008b). La virgen justiciera: el caso de María del Pilar Moreno. En G. Villadelángel Viñas (coord.), El libro rojo, una continuación (vol. I, pp. 577-584). México: Fondo de Cultura Económica.

Speckman, E. (2008c). Reforma legal y opinión pública: los códigos penales de 1871, 1929 y 1931. En A. Alvarado (ed.), La reforma de la justicia en México (pp. 565-613). México: El Colegio de México.

Speckman, E. (2016). "La bella criminal que mató por amor”. Justicia, honor femenino y adulterio (Ciudad de México, década de 1930). En Dossier: Historia Cultural del Crimen. História: Questões \& Debates, 64(1), 19-48.

Speckman, E. (2018). Instituciones de justicia y práctica judicial (Ciudad de México, 19291971). (Tesis de doctorado inédita). México: unAm.

Stern, A. (2002). Madres conscientes y niños normales. En L. Cházaro (ed.), Medicina, ciencia y sociedad en México, siglo XIX (pp. 293-336). México: El Colegio de Michoacán/Universidad Michoacana de San Nicolás de Hidalgo.

Teja Zabre, A. (1936). Exposición de motivos. En Código penal para el distrito y territorios federales en materia de fuero común y para toda la república en materia de fuero federal (1931) (pp. 7-45). México: Ediciones Botas.

Torres Septién, V. (2007). "Bendita sea tu pureza": relaciones amorosas de los jóvenes católicos en México (1940-1950). En P. Gonzalbo y M. Bazant (coords.), Tradicio- 
nes y conflictos: historias de la vida cotidiana en México e Hispanoamérica (pp. 385-413). México: El Colegio de México/El Colegio Mexiquense.

Torres Septién, V. (2013). Amor desde la práctica discursiva de la Iglesia católica preconciliar (1930-1970). En P. Gonzalbo (coord.), Amor e historia: la expresión de los afectos en el mundo de ayer (pp. 441-464). México: El Colegio de México.

Trueba, C. (2004). Identidad de género. Un debate interdisciplinar. En S. E. Pérez-Gil Romo y P. Ravelo Blancas (coords.), Voces disidentes. Debates contemporáneos en los estudios de género en México (pp. 57-92). México: CIEsAs/Miguel Ángel Porrúa/Cámara de Diputados.

Urías Horcasitas, B. (2007). Historias secretas del racismo (1920-1950). México: Tusquetes. Zemon-Davis, N. (1991). Formas de la historia social. Historia Social, 10, 177-182. 